\title{
Nano-Surface Generation Using Low-Pressure Super-Finishing With Fine Diamond Stones"
}

\author{
Sachiko OGAWA $^{* *}$, Eiichi AOYAMA ${ }^{* * *}$, Toshiki HIROGAKI ${ }^{* * * *}$ \\ and Yoshiaki ONCHI ${ }^{* * * *}$ \\ **Department of Engineering, Doshisha University, \\ 1-3 Tataramiyakodani, Kyotanabe, Kyoto 610-0321, Japan \\ E-mail: eth1302@mail4.doshisha.ac.jp \\ ***Department of Science and Engineering, Doshisha University, \\ 1-3 Tataramiyakodani, Kyotanabe, Kyoto 610-0321, Japan \\ E-mail: eaoyama@mail.doshisha.ac.jp

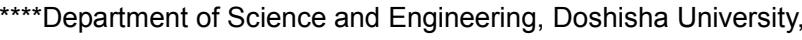 \\ 1-3 Tataramiyakodani, Kyotanabe, Kyoto 610-0321, Japan \\ *****MIZUHO Co., Ltd., \\ 82 Teradafukurojiri, Joyo, Kyoto 610-01, Japan
}

\begin{abstract}
The fixed-abrasive process has been attracting attention as an alternative to the abrasive-free process for finishing surfaces, by virtue of its capacity to improve formability and alleviate environmental problems. Here, we focus on a super-finishing method that uses fine diamond stones. Super-finishing was attempted using low-pressures $(<0.5 \mathrm{MPa})$ with diamond abrasives averaging less than $3 \mu \mathrm{m}$ in diameter. We investigated the influence of super-finishing parameters on the surface finish under low-pressure conditions for borosilicate glass. The following conclusions were reached. (1) The surface finish decreased with decreasing stone pressure for ductile cutting. By using a stone pressure of $0.1 \mathrm{MPa}$, a surface finish of $2 \mathrm{~nm} \mathrm{R}_{\mathrm{a}}$ with the $\# 12,000$ grindstone (mean grain diameter of $0.25 \mu \mathrm{m}$ ) was obtained. (2) Decreasing the mean grain diameter of the abrasive grains decreased the surface finish and could reduce crack formation. (3) A finer surface finish was obtained by increasing the volumetric grain percentage of the grindstone. (4) The maximum crossing angle minimally influenced the surface finish under low-pressure conditions. (5) We found the parameter groove aspect ratio and a method to reduce swell-out height. (6) We successfully demonstrated an evaluation method for polished surfaces and the cutting types. (7) Cracks are reduced on finished surfaces by keeping the depth of cut to less than $100 \mathrm{~nm}$ in the case of borosilicate glass.
\end{abstract}

Key words: Super-Finishing, Diamond Stone, Low-Pressure, Borosilicate Glass, Nano Surface, Fixed-Abrasive

\section{Introduction}

Hard brittle materials used as optical components and electronic parts are generally processed using loose-abrasives. Surface finish on a nano-scale order can easily be obtained by using fine abrasive grains with a mean diameter of less than $1 \mu \mathrm{m}$. Steady processing characteristics can be maintained by continuously supplying the abrasive slurry. As a result, this process is adopted in many processing methods. However, the process is inefficient, and creates a great burden on the environment. Thus, it is necessary to replace this process 
with fixed-abrasives in order to improve formability and alleviate environmental problems ${ }^{(1-10)}$. The fixed-abrasive process without abrasive slurry has thus been attracting increased attention as a method to achieve the desired surface finish.

Here, we focus on a super-finishing method that uses a fine super-abrasive stone. Super-finishing is a method for cutting and polishing with the aid of pressure, and has the potential to produce an excellent surface finish. Traditional super-finishing under $\mathrm{MPa}$-order pressure conditions is widely used for final stage finishing of precision parts such as bearings. We reasoned that the depth of cut from the grains could be reduced by lowering the processing pressure and using finer abrasive grains. Moreover, we believe that a hard and sharp super-abrasive grain, such as diamond, would be suitable for cutting surfaces under low-pressures. There have been very few reports dealing with super-finishing under low-pressures.

In the present study, super-finishing of borosilicate glass was attempted using low-pressures with diamond abrasives averaging less than $3 \mu \mathrm{m}$ in diameter. We aimed to obtain a surface finish on the nano-order using fixed-abrasive stones.

\section{Surface generation model}

Figure 1 shows the conventional surface generation model ${ }^{(11)}$. It is assumed that when an abrasive grain cuts the surface, each cutting edge scratches the surface at a comparatively low speed. It is known that at low speeds, static and dynamic stresses are almost the same. Therefore, we assume the following conditions in order to theoretically obtain the depth of cut by a grain. It is assumed that the surface of the grindstone comes into contact with the surface of the workpiece under a constant load.

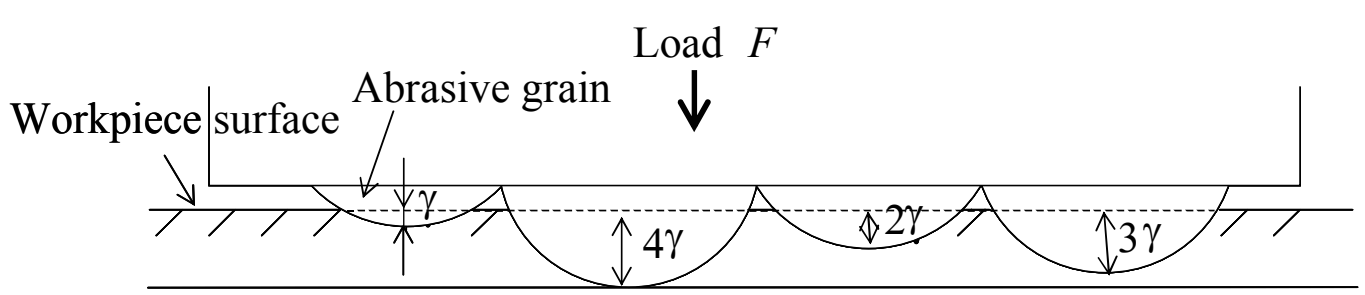

Fig. 1 Conventional surface generation model

(1) The shape of the cutting edge is directly transcribed onto the surface of the workpiece (the interfering part of the surface contacting the abrasive grain is removed in the form of chips, and swell-outs are not generated).

(2) The abrasive grains are spherical having equal diameters. In addition, they are distributed evenly, with an equal gap, $\gamma_{2}$ between neighboring grains.

(3) Dropout, wear and crushing of the abrasive grains do not occur, and clogging does not occur.

Equation (1) represents the maximum depth of cut $\delta_{\max }$ for an abrasive grain. The equation is derived from the balance between the load $F$, as shown in Fig. 1 , on the grindstone and the total reactive force to the abrasive grain. 


$$
\delta_{\max }=d_{g} \cdot \sqrt{\frac{P_{n}}{3 \cdot P_{m} \cdot V_{g}}}
$$

Here, $P_{n}$ is the stone pressure (the load on the grindstone divided by the surface area of the grindstone), $d_{g}$ is the mean diameter of the abrasive grains, $P_{m}$ is the yield stress of the workpiece, and $V_{g}$ is volumetric grain percentage. This equation suggests that the maximum depth of cut is proportional to the mean diameter of the abrasive grains and to the square root of the stone pressure. It is clear from this equation that a smaller grain size, decreased stone pressure, and higher volumetric grain percentage will be effective in improving the surface finish.

\section{Experimental procedure}

We developed a prototype of a super-finishing tool for a vertical type machining center (see Fig. 2). Since a linear guide was used in the tool, we could provide constant pressure. Stone pressure was controlled by applying the load on the pressure part with the weight. A low load was applied by adjusting the weight on the grindstone. The stone pressure can be made extremely low. We made a super-finishing tool path which had a maximum crossing angle based on super-finishing theory by a CNC control, as shown in Fig. 3, and used a vertical type machining center for the experiment. Finishing area was $5 \mathrm{~mm} \times 5 \mathrm{~mm}$ as shown in Fig. 3. In this super-finishing path, as indicated in Fig. 3, the leading edge and trailing edge change continuously. However, under low-pressure conditions, influence of crossing between abrasive grains and surface generated on dropout assumed to be little.

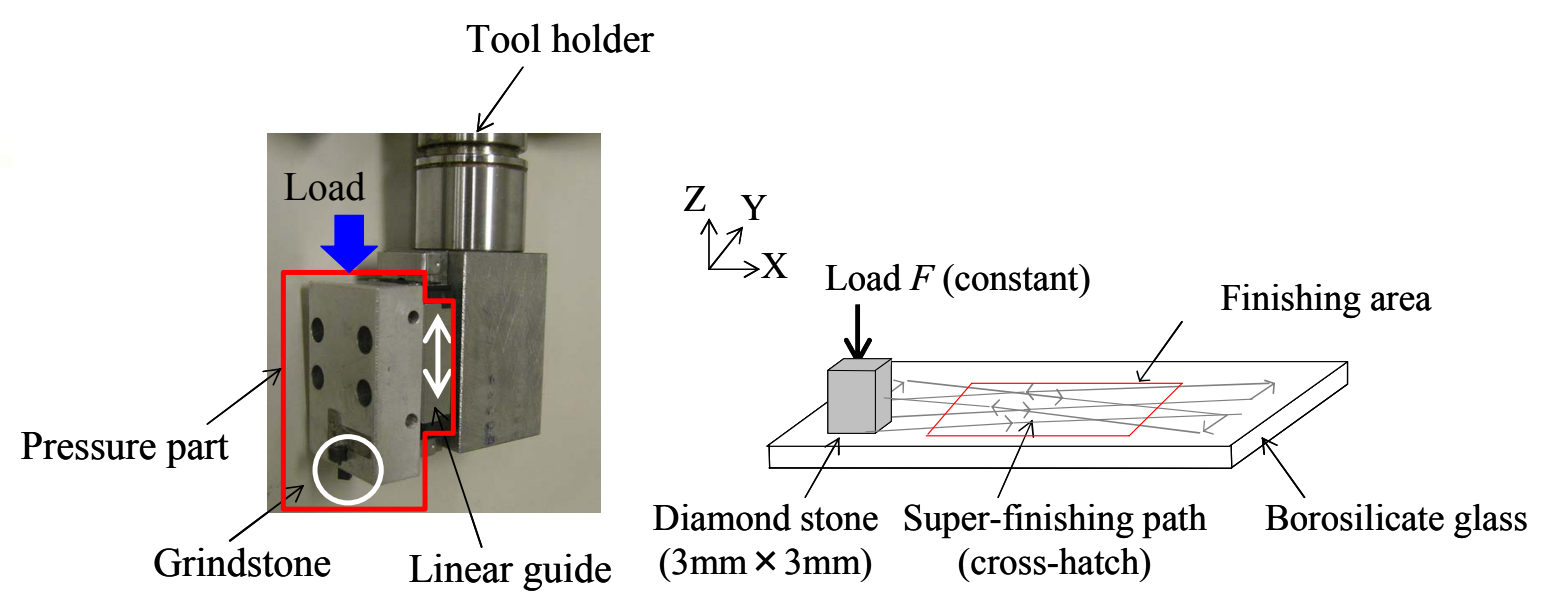

Fig. 2 Super-finishing tool used in the study

Fig. 3 Super-finishing method

Diamond stones were used in the experiment. The workpiece was a borosilicate glass, and its surface was the target of the super-finishing. Tables 1 and 2 show the specifications of the grindstone and the workpiece. Water was used as a lubricant.

Table 1 Specifications of the grindstone tested

\begin{tabular}{|c|c|}
\hline Abrasive grain & Diamond \\
\hline Grain size & $\# 4000, \# 8000, \# 12000, \# 16000$ \\
\hline Mean grain diameter $d_{g} \mu \mathrm{m}$ & $3,1,0.25,0.1$ \\
\hline Bonding material & Vitrified \\
\hline Volumetric grain percentage $V_{g}$ & $23.5-31.5$ \\
\hline Stone size $\mathrm{mm}^{3}$ & $3 \times 3 \times 4$ \\
\hline
\end{tabular}


Table 2 Specifications of the workpiece

\begin{tabular}{|c|c|}
\hline Material & Borosilicate glass \\
\hline Main component & $\mathrm{SiO}_{2}$ \\
\hline Size $\mathrm{mm}^{3}$ & $26 \times 76 \times 1$ \\
\hline Hardness & $630 \mathrm{HV}$ \\
\hline Roughness $\mathrm{nmR}_{\mathrm{a}}$ & 2 \\
\hline
\end{tabular}

Pre-finishing was performed prior to the actual finishing to keep the initial condition of the grindstone and the workpiece the same. Tables 3 and 4 list the pre-finishing and finishing conditions used. In Table 4, pre-finishing stone which was the grain size used in pre-finishing was changed by each grain size used in finishing.

Table 3 Pre-finishing conditions

\begin{tabular}{|c|c|c|c|c|}
\hline Grain size & $\# 4000$ & $\# 8000$ & $\# 8000$ & $\# 12000$ \\
\hline Stone pressure $P_{n} \mathrm{MPa}$ & 0.5 & 0.5 & 0.1 & 0.1 \\
\hline Maximum crossing angle $\Theta_{\max }$ deg. & \multicolumn{4}{|c|}{30} \\
\hline Cutting speed $V \mathrm{~m} / \mathrm{min}$ & \multicolumn{4}{|c|}{2.5} \\
\hline Oscillation amplitude mm & \multicolumn{4}{|c|}{0.5} \\
\hline Pre-finishing area $\mathrm{mm}^{2}$ & \multicolumn{4}{|c|}{$5 \times 5$} \\
\hline Cutting distance $\mathrm{m}$ & \multicolumn{4}{|c|}{5} \\
\hline Surface roughness after pre-finishing $\mathrm{nmR}_{\mathrm{a}}$ & 25 & 15 & 6 & 3 \\
\hline
\end{tabular}

Table 4 Finishing conditions

\begin{tabular}{|c|c|c|c|c|}
\hline Grain size & $\# 4000$ & $\# 8000$ & $\# 12000$ & $\# 16000$ \\
\hline Pre-finishing stone & $\# 4000$ & $\# 8000$ & $\# 8000$ & $\# 12000$ \\
\hline Stone pressure $P_{n} \mathrm{MPa}$ & \multicolumn{4}{|c|}{$0.1-0.5$} \\
\hline Volumetric grain percentage $V_{g} \%$ & \multicolumn{4}{|c|}{$23.5-31.5$} \\
\hline Maximum crossing angle $\Theta_{\max }$ deg. & \multicolumn{4}{|c|}{$0.1-60$} \\
\hline Cutting speed $V \mathrm{~m} / \mathrm{min}$ & \multicolumn{4}{|c|}{0.5 .5} \\
\hline Oscillation amplitude mm & \multicolumn{3}{|c|}{$5 \times 5$} \\
\hline Finishing area $\mathrm{mm}^{2}$ & \multicolumn{4}{|c|}{} \\
\hline
\end{tabular}

We determined the cutting distances to remove the same volume using Preston's law (Eq. 2) ${ }^{(12)}$. First, we investigated the relationship between cutting distance and the surface finish, $R_{a}$, for each grain size using a stone pressure of $0.1 \mathrm{MPa}$ (see Fig. 4). Here, $R_{a}$ is the average roughness. Next, we derived the cutting distance at which the surface finish reached a constant value. On the basis of this value, cutting distances were derived for each stone pressure using Preston's law, represented by Eq. (2). Here, $T_{v}$ represents the stock removal of the workpiece, $k$ is a constant, $P_{n}$ is the stone pressure, $V$ is the cutting speed, and $t$ is the cutting time. As a result, cutting distances, as shown in Table 5, were used. In this study, stone wear was little so that it could not be measured by a micrometer. Steady contact between the grindstone and the workpiece was judged by roughness convergent of the workpiece while whole processing.

$$
T_{v}=k \cdot P_{n} \cdot V \cdot t
$$




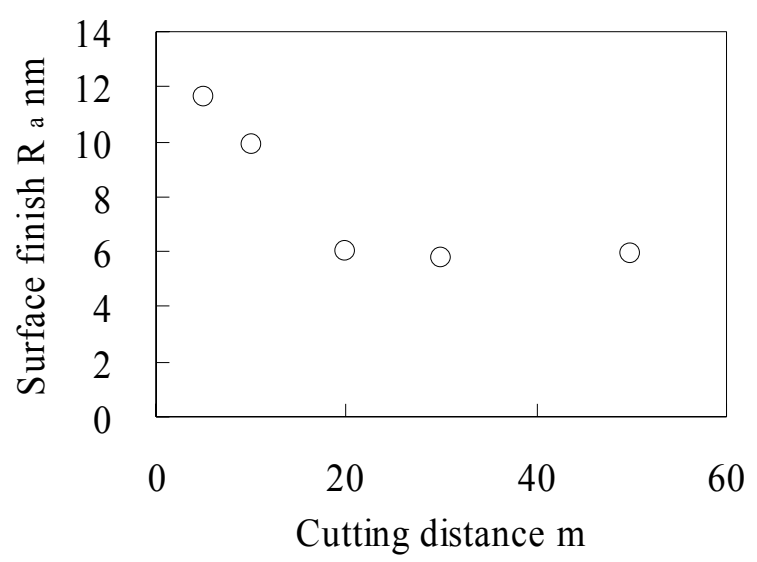

Fig. 4 Variation of surface finish with cutting distance (\#8000, $P_{n}=0.1 \mathrm{MPa}, V_{g}=28.3 \%, \Theta_{\max }=10$ deg., $V=2.5 \mathrm{~m} / \mathrm{min}$ )

Table 5 Cutting distances

\begin{tabular}{|c|c|c|c|c|c|}
\hline $\begin{array}{c}\text { Stone pressure } \\
P_{n} \mathrm{MPa}\end{array}$ & 0.1 & 0.2 & 0.3 & 0.4 & 0.5 \\
\hline$\# 4000$ & $30 \mathrm{~m}$ & $15 \mathrm{~m}$ & $10 \mathrm{~m}$ & $7.5 \mathrm{~m}$ & $6 \mathrm{~m}$ \\
\hline$\# 8000$ & $30 \mathrm{~m}$ & $15 \mathrm{~m}$ & $10 \mathrm{~m}$ & $7.5 \mathrm{~m}$ & $6 \mathrm{~m}$ \\
\hline$\# 12000$ & $30 \mathrm{~m}$ & $15 \mathrm{~m}$ & $10 \mathrm{~m}$ & $7.5 \mathrm{~m}$ & $6 \mathrm{~m}$ \\
\hline$\# 16000$ & $30 \mathrm{~m}$ & $15 \mathrm{~m}$ & $10 \mathrm{~m}$ & $7.5 \mathrm{~m}$ & $6 \mathrm{~m}$ \\
\hline
\end{tabular}

We examined the surface finish of the workpiece with a scanning probe microscope (SHIMADZU, SPM-9500). We characterized the workpiece and grindstone using a scanning electron microscope (HITACHI, S-3000N).

\section{Results and discussion}

\subsection{Influence of stone pressure on surface finish}

Figure 5 shows the variation of the surface finish as a function of stone pressure $P_{n}$. Figure 6 shows SPM scans of the finished surface. The histogram shows frequency distribution of height position which is allocated in color bar. The surface finish decreased with decreasing stone pressure, as shown in Fig. 5. The experimental trends are in agreement with Eq. (1) as far as the stone pressure $P_{n}$ is concerned. However, in the case of $\# 4000$, the surface finish did not decrease with decreasing stone pressure as much as for the other grain sizes. It is thought that in this case cracks are formed even at low-pressures, as shown in Fig. 6 (b). Here, cracks are defined as irregularities without ductile cutting, and judged by SPM measurement of two parts on the finished surface. Thus, not only a lower pressure but also finer abrasive grains are likely necessary to obtain a fine surface finish and to reduce cracks. Moreover, using finer abrasive grains, such as \#8000, \#12000, \#16000, ductile cutting was achieved, as shown in Fig. 6 (a). The pressure used during super-finishing is typically about $1-3 \mathrm{MPa}^{(1),(12-14)}$, whereas we employed a maximum stone pressure of $0.5 \mathrm{MPa}$. Using a low stone pressure and fine abrasive grains, we could reduce cracks for borosilicate glass. By using a stone pressure of $0.1 \mathrm{MPa}$, we could obtain a surface finish of $4 \mathrm{~nm} \mathrm{R}_{\mathrm{a}}$ with the $\# 8000$ grindstone (mean grain diameter of $1 \mu \mathrm{m}$ ) and 2 $\mathrm{nm} \mathrm{R}_{\mathrm{a}}$ with the \#12,000 grindstone (mean grain diameter of $0.25 \mu \mathrm{m}$ ). 


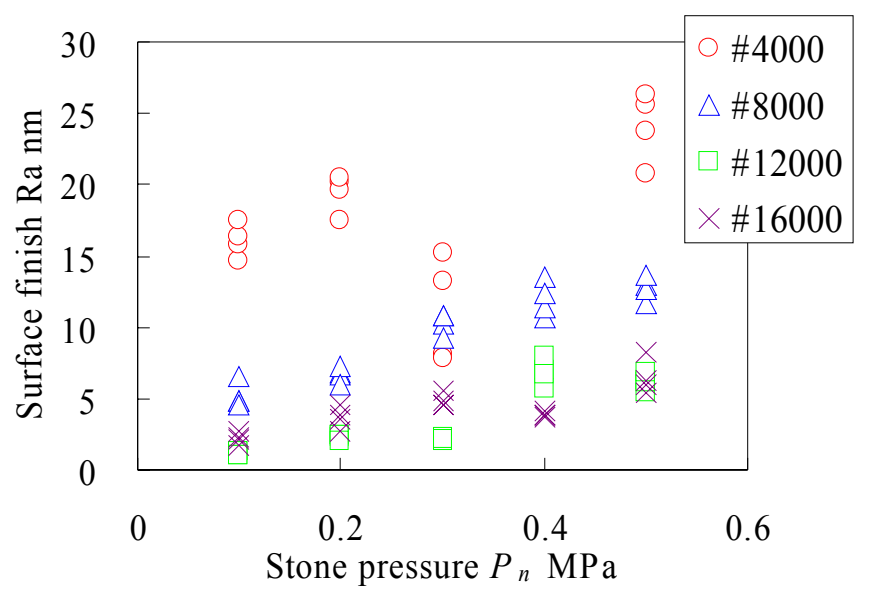

Fig. 5 Variation of surface finish as a function of stone pressure $P_{n}$

$$
\left(V_{g}=28.3 \%, \Theta_{\max }=10 \mathrm{deg} ., V=2.5 \mathrm{~m} / \mathrm{min}\right)
$$

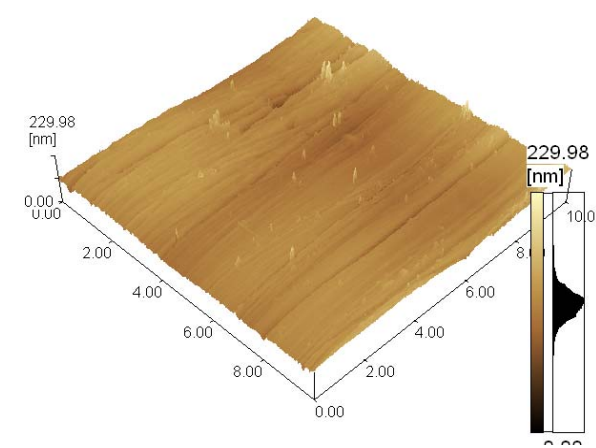

(a) Finished surface without cracks

(\#8000, $P_{n}=0.2 \mathrm{MPa}, V_{g}=28.3 \%, \Theta_{\max }=10$ deg., $V=2.5 \mathrm{~m} / \mathrm{min}$ )

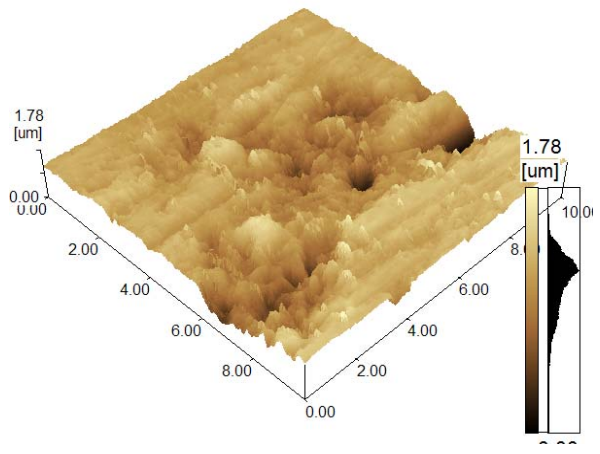

(b) Finished surface with cracks

Fig. 6 Finished surfaces

\subsection{Influence of mean grain diameter on surface finish}

Figure 7 shows the variation of surface finish as a function of mean grain diameter $d_{g}$. The surface finish decreased with decreasing mean grain diameter. Moreover, the surface finish was proportional to the mean grain diameter, except in the case of \#4000 (mean grain diameter of $3 \mu \mathrm{m}$ ), for which cracks were formed. The surface finish results are thus in agreement with Eq. (1) with regards to the mean grain diameter $d_{g}$ except in the case of $\# 4000$. Figure 8 shows SPM images of the finished surfaces using the various grain sizes. Figure 9 shows SEM images of the different stone surfaces. The surface grooves in the workpiece became finer with decreasing grain size, as seen in Fig. 8. This is an indication of shallow depth of cut. It is thought that the shallow depths of cut are generated because the force to an abrasive grain becomes small by small height distribution of abrasive grains as shown in Fig. 9, and the depths of cut are thus reduced. Moreover, it is thought that this is an indication of cutting with a sharp diamond edge, and not burnishing process that minimally makes stock removal with low efficiency. We could also reduce cracks by using fine abrasive grains having a mean diameter of $1 \mu \mathrm{m}$ or less, and obtain fine surface finishes with ductile cutting by using fine abrasive grains. 


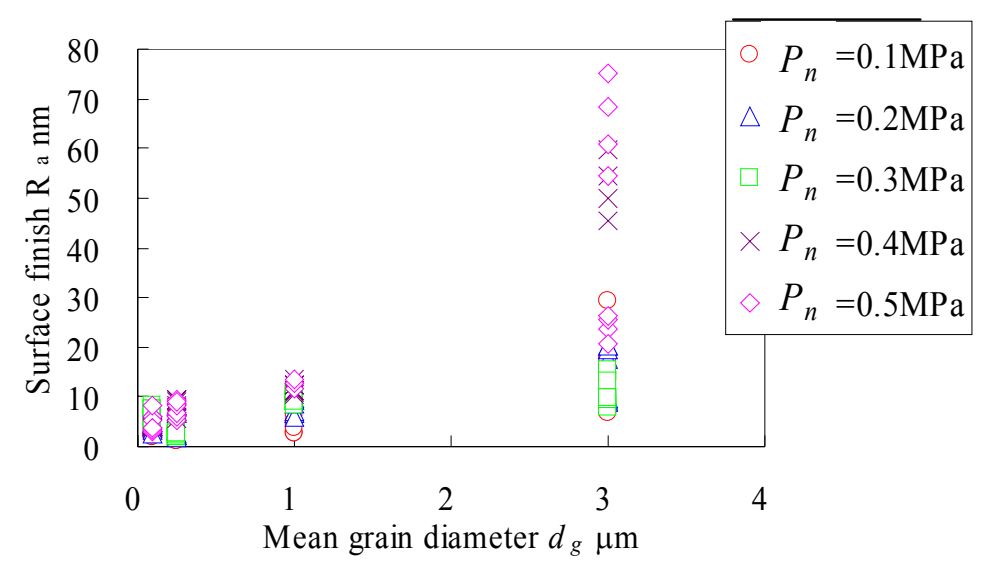

Fig. 7 Variation of surface finish as a function of mean grain diameter $d_{g}$

$$
\left(V_{g}=28.3 \%, \Theta_{\max }=10 \mathrm{deg} ., \quad V=2.5 \mathrm{~m} / \mathrm{min}\right)
$$

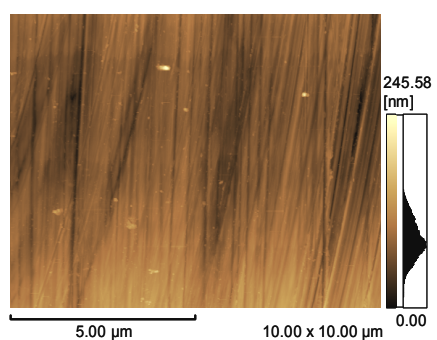

(a) $\# 8000$

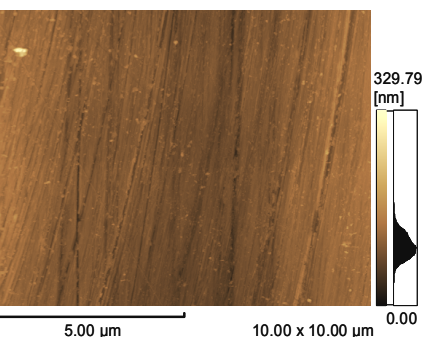

(b) \#12000

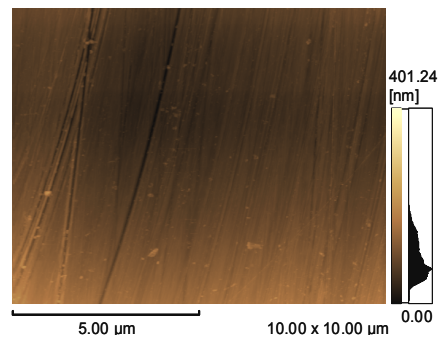

(c) $\# 16000$

Fig. 8 Finished surfaces

$\left(P_{n}=0.2 \mathrm{MPa}, V_{g}=28.3 \%, \Theta_{\max }=10 \mathrm{deg} ., V=2.5 \mathrm{~m} / \mathrm{min}\right)$

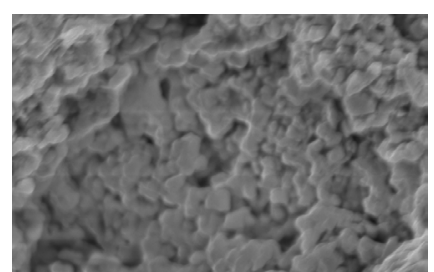

(a) $\# 8000$

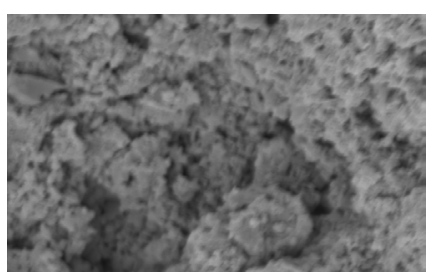

(b) $\# 12000$

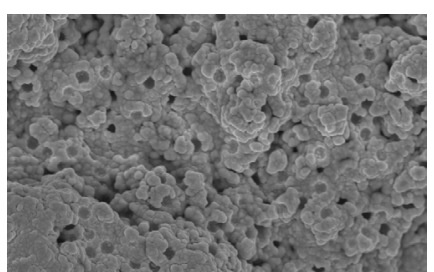

(c) $\# 16000$

$2 \mu \mathrm{m}$

Fig. 9 SEM micrographs of the stone surfaces with various grain sizes

$$
\left(V_{g}=28.3 \%\right)
$$

\subsection{Influence of volumetric grain percentage on surface finish}

Figure 10 shows the stone surface roughness before finishing with various volumetric grain percentages $V_{g}$. Here, $\mathrm{R}_{\mathrm{z}}$ is the value from peak to valley. Figure 11 shows the stone surfaces with various $V_{g}$ before finishing. Figure 12 shows the variation in surface finish of the workpiece with $V_{g}$. Increasing the volumetric grain percentage $V_{g}$ decreased the surface finish, as shown in Fig. 12. From Eq. (1), the depth of cut is proportional to the square root of $1 / V_{g}$. The experimental results show the same trend with $V_{g}$. This improvement in the surface finish was caused by the low roughness of the stone surface before finishing. Generally, the shape of the cutting edge is directly transcribed onto the surface of the workpiece $^{(11)}$. Thus, when the stone surface has a low roughness, the workpiece becomes fine, too. Increasing $V_{g}$ decreased stone surface roughness as shown in Fig. 10, so that it 
was thought that the surface finish became fine when the grindstone had a high $V_{g}$. It was found that even in the case of low-pressure super-finishing of borosilicate glass, this transcription was successful.

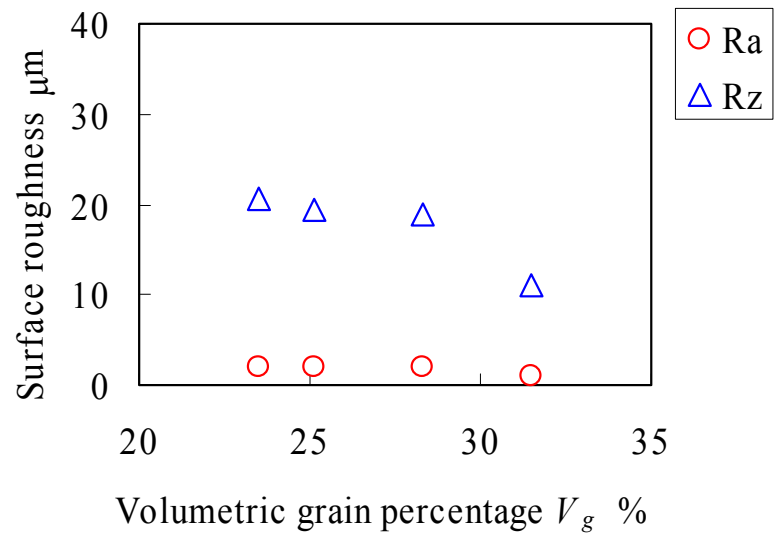

Fig. 10 Stone surface roughness at various volumetric grain percentages $V_{g}(\# 8000)$

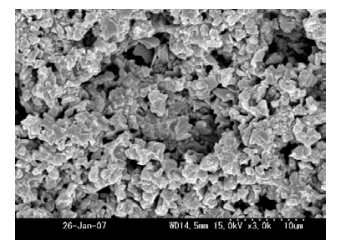

(a) $V_{g}=23.5 \%$

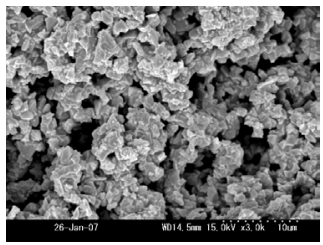

(b) $V_{g}=25.5 \%$

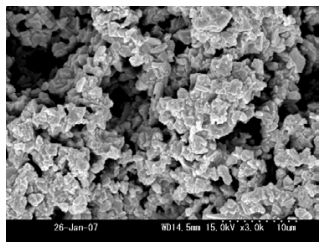

(c) $V_{g}=28.3 \%$

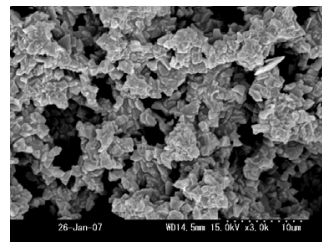

(d) $V_{g}=31.5 \%$

Fig. 11 Stone surfaces with various volumetric grain percentages $V_{g}(\# 8000)$

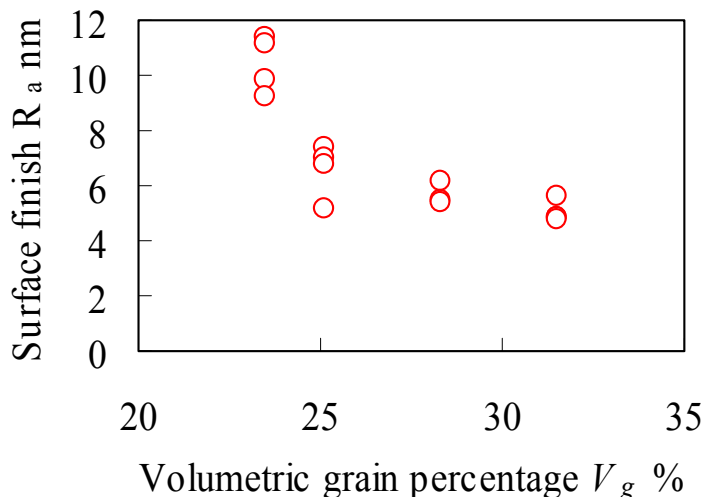

Fig. 12 Variation of surface finish with various volumetric grain percentages $V_{g}$

( \#8000, $P_{n}=0.1 \mathrm{MPa}, \Theta_{\max }=10$ deg., $V=2.5 \mathrm{~m} / \mathrm{min}$ )

\subsection{Influence of maximum crossing angle on surface finish}

Figure 13 shows the variation in surface finish as a function of the maximum crossing angle, $\Theta_{\max }$. Generally, the maximum crossing angle is an important parameter in conventional super-finishing. Figure 14 shows the definition of the maximum crossing angle. The surface finish was little changed with varying maximum crossing angle, as seen in Fig. 13. It is known that the surface finish increases with increasing maximum crossing angle for the super-finishing of hardened steel ${ }^{(12-14)}$. This is because increasing the crossing angle reduces the amount of bonding material holding the abrasive grains, which increases the force on abrasive grains of the leading edge, resulting in dropout of the grains. However, in the present method, super-finishing was performed under low-pressure conditions so that it was thought that grain dropout did not occur when abrasive grains crossed with the workpiece surface which was already generated. The leading edge and trailing edge 
changed continuously along the super-finishing path. This is different from conventional idea of super-finishing. Moreover, a grindstone has many pores, and the chips generated are fine and not as hard as hardened steel. Thus, it is thought that the present process differs from that observed in the case of hardened steel. As a result, the maximum crossing angle barely influences the surface finish in low-pressure super-finishing of glass using a fine diamond stone.

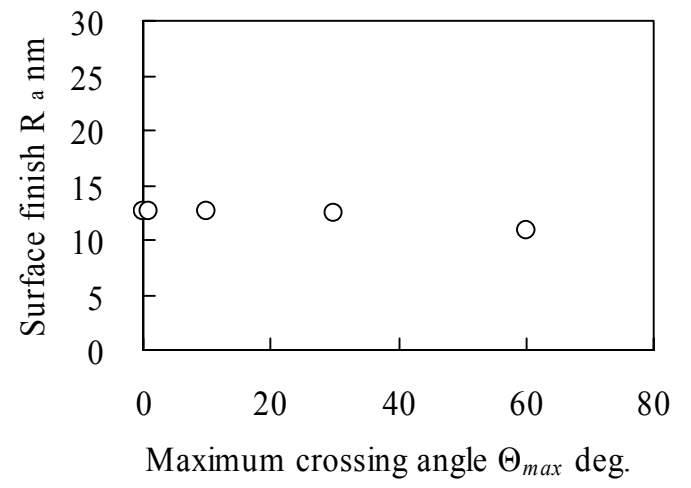

Fig. 13 Variation in surface finish as a function of maximum crossing angle $\Theta_{\max }$

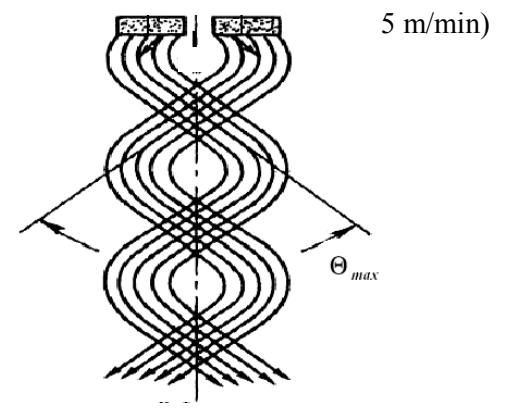

Fig. 14 Definition of the maximum crossing angle $\Theta_{\max }$

\subsection{Influence of cutting speed on surface finish}

Figure 15 shows the variation in surface finish as a function of cutting speed $V$. The surface finish achieves a nearly constant value when the cutting speed exceeds $\sim 3.0 \mathrm{~m} / \mathrm{min}$. Generally, in the polishing of ductile materials such as hardened steel, increasing the cutting speed causes a dynamic pressure effect in the presence of a lubricant, and the grindstone floats ${ }^{(12)}$. In this study, since the super-finishing was performed under low-pressure, the influence of the cutting speed on the actual stone pressure was presumably significant. Thus, real contact pressure was thought to be one of the reasons that the surface finish increased under low cutting speed condition. Moreover, it is known that swell-out becomes large in low cutting speed ${ }^{(12)}$. Thus, high swell-out under low cutting speed condition was thought to be another reason. However, high cutting speeds should be avoided because vibration might occur during processing and influence the surface finish.

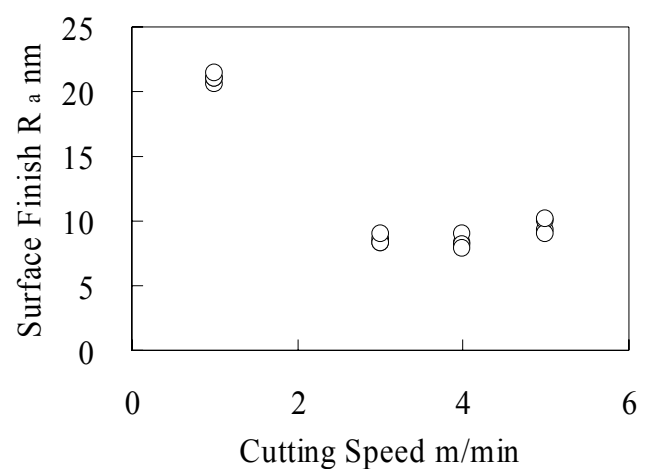

Fig. 15 Variation in surface finish as a function of cutting speed $V$

( $\# 8000, P_{n}=0.1 \mathrm{MPa}, V_{g}=28.3 \%, \Theta_{\max }=10$ deg.) 


\subsection{Improvement of surface finish taking swell-out into account}

Equation (1) gives the theoretical depth of cut without taking swell-out into account. However, it was clear that ductile cutting could be obtained for borosilicate glass so that it was necessary to consider swell-out to decrease surface finish. Especially in low-speed super-finishing with a small depth of cut, we need to pay attention to the swell-out. Minimizing the swell-out height will also help improve the surface finish. To measure swell-out, scratch tests with fine diamond stones were performed for glass. The experimental conditions were $\# 8000, V_{g}=28.3 \%, V=2.5 \mathrm{~m} / \mathrm{min}$, and a path without crossing angle was scratched. Waviness curve was measured in a vertical direction to scratch, and swell-out was figured. To decrease swell-out, a parameter that correlates with the swell-out must be selected. We selected the groove aspect ratio as the appropriate parameter. The groove aspect ratio is then defined as:

$$
\text { Groove aspect ratio }=\frac{\text { Groovewidth }}{\text { Groovedepth }}
$$

Figure 16 illustrates the definitions of a groove and swell-out on the workpiece surface. Figure 17 illustrates the relationship between the groove aspect ratio and swell-out height under various stone pressures. The swell-out height increased with decreasing groove aspect ratio. That is, the narrower and deeper the groove, the higher was the swell-out. Here, the edge contacting with the workpiece is assumed to be spherical. Thus, decreasing the swell-out height is effective only when the extreme edge interferes with the workpiece, since the groove aspect ratio is large. It can be stated that cutting using low-pressures and fine abrasive grains is effective even as a condition of interference in reducing the swell-out height, and not only by decreasing the groove depth. We could decrease the swell-out height by using an aspect ratio of more than 5 .

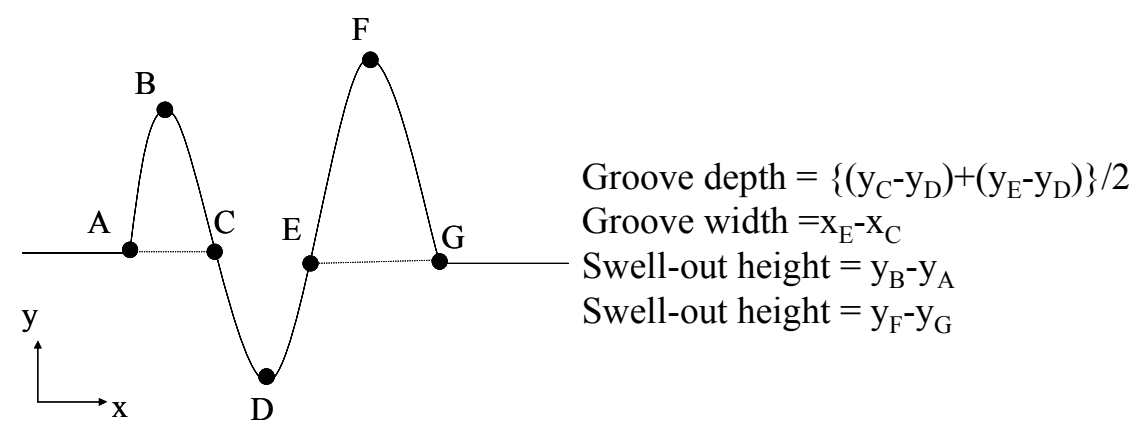

Fig. 16 Definition of swell-out

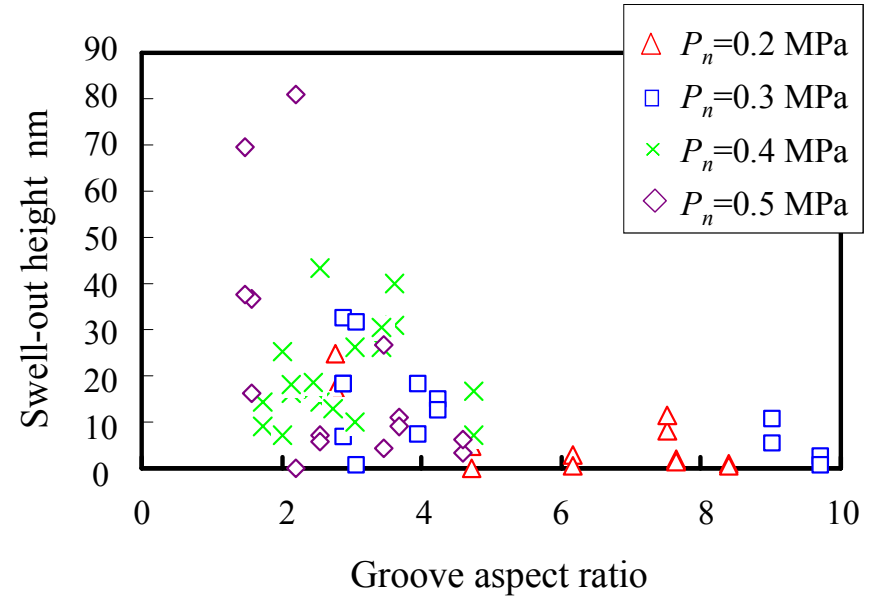

Fig. 17 Relationship between groove aspect ratio and swell-out height under various stone pressures (\#8000) 


\subsection{Evaluation of surface properties by using bearing ratio}

The preceding sections mainly described the investigation of the surface finish. However, we have also found a way of obtaining crack-less and small-swell-out conditions. Here, we attempt to characterize the polished glass surface thoroughly and cutting types while the processing. First, we use the parameter $t_{p}$ to characterize the surface by using bearing ratio. Equation (4) and Figure 18 show the definition of $t_{p}$. This parameter indicates a ratio of interfering length with the roughness curve to length $L$ in the case that the roughness curve is cut with each cutting level.

$$
t_{p}=\frac{\eta_{p}}{L} \times 100
$$

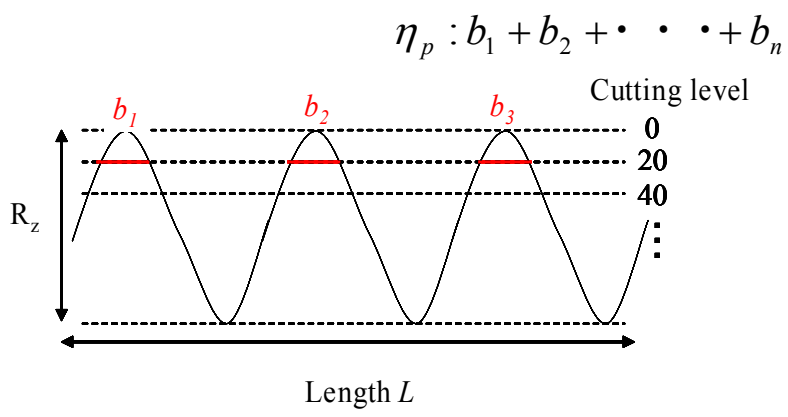

Fig. 18 Definition of bearing ratio

We assumed some cutting models as single shapes which were generated on the finished surface. Figure 19 shows three cutting models, viz., crack type, sine wave as normal cutting type, and burnishing type. The burnishing type model has a low sine wave indicating partly plastic deformation. Figure 20 shows the evaluation of the cutting models using Eq. (4). The trends clearly differ from each other for the three cases in Fig. 20. Thus, we regarded a polished surface as an assembly of each cutting model, and attempted to evaluate the finished surface using Eq. (4). Figure 21 shows an evaluation of the finished surface, based on data from Fig. 7. The trends observed in the case of $\# 4000$ are in agreement with the crack-type cutting model; cracks were formed using \#4000. Thus, it is concluded that the crack-type cutting model is well evaluated using the bearing ratio. The trends of the other conditions in Fig. 21 are close to those of the cutting models in Fig. 20. We thus evaluated a super-finished borosilicate glass surface using cutting models and bearing ratio, and were able to predict the finished surface and the cutting process.

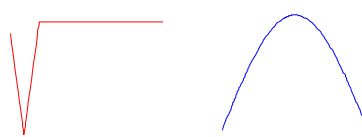
(a) Crack type
(b) Normal cutting type
(c) Burnishing type

Fig. 19 Cutting models

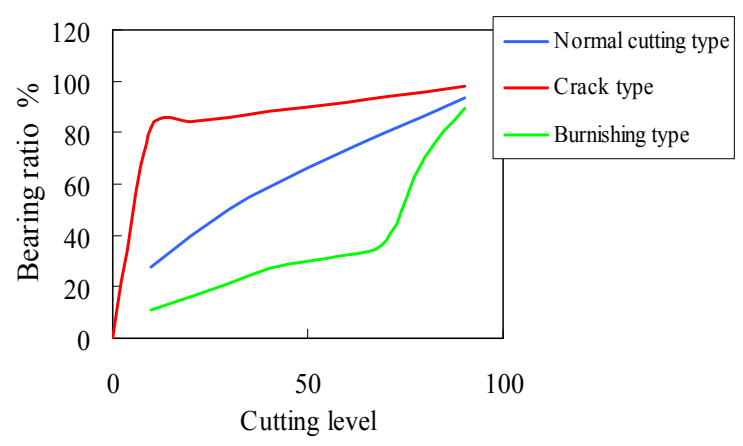

Fig. 20 Bearing ratio evaluation of cutting 


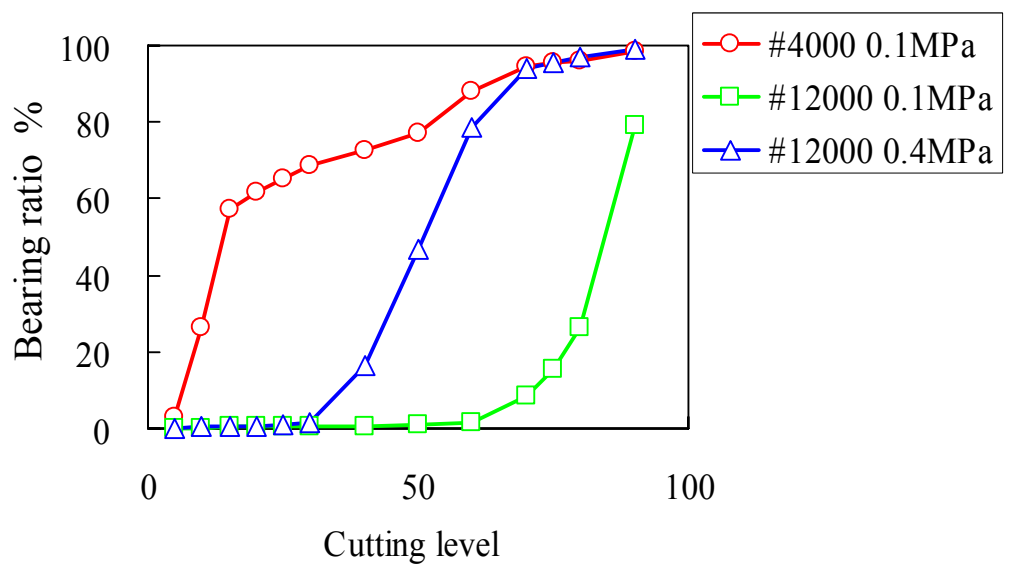

Fig. 21 Bearing ratio evaluation of finished surface

( $\left.V_{g}=28.3 \%, \Theta_{\max }=10 \mathrm{deg} ., V=2.5 \mathrm{~m} / \mathrm{min}\right)$

\subsection{Investigation of conditions for the occurrence of cracks}

Figure 22 shows the variation of the groove depth with stone pressure, and the conditions when cracks occurred. The definition of the groove depth is shown in Fig. 16. In this experiment, cracks occurred when the depths of the grooves were more than $100 \mathrm{~nm}$, and were not affected by the stone pressure. These depths of the grooves represent the same conditions as those when $\# 4000$ stones were used. It is clear that even if low-pressures are used, cracks will still occur with the $\# 4000$ stone. This phenomenon is also in agreement with Fig. 21 model. Generally, the condition for the occurrence of cracks is about $100 \mathrm{~nm}$ depth of cut in the case of borosilicate glass ${ }^{(15)}$. Thus, the present experimental result is adequate and the depth of groove should be controlled to be less than $100 \mathrm{~nm}$.

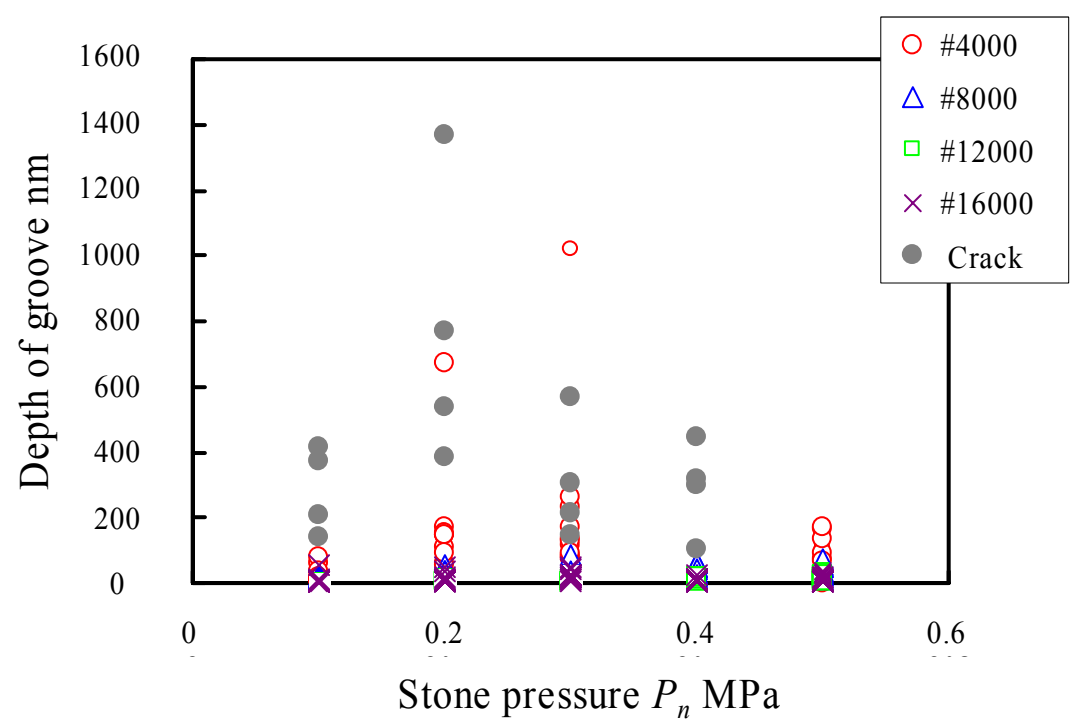

Fig. 22 Depth of groove when cracks occur

$\left(V_{g}=28.3 \%, \Theta_{\max }=10\right.$ deg., $\left.V=2.5 \mathrm{~m} / \mathrm{min}\right)$ 


\section{Conclusions}

The following conclusions were obtained in this study.

(1) The surface finish decreased with decreasing stone pressure for ductile cutting. By using a stone pressure of $0.1 \mathrm{MPa}$, a surface finish of $2 \mathrm{~nm} \mathrm{R} \mathrm{R}_{\mathrm{a}}$ with the $\# 12,000$ grindstone (mean grain diameter of $0.25 \mu \mathrm{m}$ ) was obtained.

(2) Decreasing the mean grain diameter of the abrasive grains decreased the surface finish and could reduce crack formation.

(3) A finer surface finish was obtained by increasing the volumetric grain percentage of the grindstone.

(4) The maximum crossing angle minimally influenced the surface finish under low-pressure conditions.

(5) We found the parameter groove aspect ratio and a method to reduce swell-out height.

(6) We successfully demonstrated an evaluation method for polished surfaces and the cutting types.

(7) Cracks are reduced on finished surfaces by keeping the depth of cut to less than $100 \mathrm{~nm}$ in the case of borosilicate glass.

\section{References}

(1) Matsumori, N., and Onchi, Y., Advaced Superfinishing with CBN and Diamond Stones, SME Technical Paper, 1993, MR93-333.

(2) Okayama, H., and Wate, J., The New Water Based Coolant's Development Fitted for Sub-mirror Surface Finish Process in the Production, Advances in Abrasive Technology III, 2000, pp. 263-270.

(3) Buijs, M., and Korpel Van Houten, K., A Model for Lapping of Glass, Journal of Material Science, Vol. 28, 1993, pp. 3014-3020.

(4) Nakagawa, H., et al, Honing Process on a Machining Center, Proc. Int. Conf. on Advanced Manufacturing Systems and Manufacturing Automation, 2000, pp. 113-116.

(5) Yoshino, M., et al, Machining of Hard-brittle Materials by a Single Point Tool Under External Hydrostatic Pressure, Journal of Manufacturing Science and Engineering, Vol. 127, 2005.

(6) Onchi, Y., Matsumori, N., Igawa, N., Shimada, S., Cutting Mechanism of Superfinishing by Fine CBN Stone, Journal of the Japan Society of Precision Engineering, Vol. 62, No. 5, 1996, pp.666-670.

(7) Higuchi, M., Yamaguchi, T., Matsumori, N., Ogura, H., Geometric Modeling of Vitrified Superabrasive Stone Surface (in Japanese), Transaction of the Japan Society of Mechanical Engineering C, Vol. 73, No. 732, 2007, pp. 2381-2386.

(8) Ogura, H., Matsumori, N., New superfinishing stone with controlled pore structures (in Japanese), Journal of the Japan Society for Abrasive Technology, Vol. 48, No. 7, 2004, pp. $362-366$.

(9) Matsumori, N., Yamamoto, A., Influence of Superfinishing Stone Specification on Critical Stone Pressure and Finishing Characteristics at the Pressure: Study on the Elevation of Finishing Ability of Superfinishing Stone ( $2^{\text {nd }}$ Report) (in Japanese), Journal of the Japan Society of Precision Engineering, Vol. 41, No. 488, 1975, pp. 884-889.

(10) Matsumori, N., Yamamoto, A., Critical Stone Pressure as a Characteristics Concerned with Finishing Ability in Superfinishing: Study on the Elevation of Finishing Ability of Super-finishing Stone ( ${ }^{\text {st }}$ Report) (in Japanese), Journal of the Japan Society of Precision Engineering, Vol. 40, No. 477, 1974, pp. 852-857.

(11) Adachi, K., et al, Material Processing (in Japanese), Asakurashoten, 2008. 
(12) Matsui, M., Superfinishing and its Mechanism (in Japanese), Yokendo, 1965.

(13) AOYAMA, E., HIROGAKI, T., ONCHI, Y., YANAGITANI, K., KAWABATA, N., The Research on Abrasive Grain Falling in the Super-finishing Process by CBN Stone (in Japanese), Transaction of the Japan Society of Mechanical Engineering C, Vol. 68, No. 667, 2002, pp. 980-986.

(14) AOYAMA, E., ONCHI, Y., HIROGAKI, T., OKUDA, M., IRIE, A., Study on Super-finishing by CBN Stone: Estimation of Cutting Performance Using Average Crossing Angle (in Japanese), Transaction of the Japan Society of Mechanical Engineering C, Vol. 64, No. 623, 1998, pp. 2747-2755.

(15) TAMAKI, J., SATO, G., MAEKAWA, K., YAN, J., KUBO, A., Effect of Cutting Edge Shape of Diamond Abrasive Grain in Ductile Mode Grinding of Optical Glass: Measurement of Critical Depth of Cut by Means of Single Grit Diamond Cutting (in Japanese), Journal of the Japan Society for Abrasive Technology, Vol. 49, No. 6, 2005, pp. 335-340. 